\title{
Clinical features and outcomes of COVID-19 patients with gastrointestinal symptoms
}

\author{
Chao Cao ${ }^{1 \dagger}$, Meiping Chen ${ }^{1 \dagger}, \mathrm{Li} \mathrm{He}^{2 \dagger}$, Jiao Xie ${ }^{3}$ and Xiaomin Chen ${ }^{4 *}$
}

Keywords: Clinical features, Coronavirus disease 2019, Gastrointestinal symptoms

The emergence of coronavirus disease 2019 (COVID-19), which caused by severe acute respiratory syndrome coronavirus 2 (SARS-CoV-2), has put unprecedented challenges on the public health $[1,2]$. It is well- known that most of the infected patients presented with fever or respiratory manifestations, while a portion of patients presented with gastrointestinal (GI) symptoms [2]. In early published study from the USA, SARS-CoV-2 viral RNA has been present in the feces of the illness [3]. However, part of COVID-19 patients present GI symptoms at the onset of diseases may be overlooked by clinicians [4].

Our experience was conducted in Ningbo First Hospital, Jingzhou Central Hospital, and Hubei Provincial Hospital of Integrated Chinese \& Western Medicine. One hundred fifty-seven patients we treated were diagnosed as COVID-19 according to the World Health Organization interim guidance [5]. Nasopharyngeal swabs and chest computed tomography were collected from all patients. Demographic data, symptoms, laboratory values, comorbidities, and clinical outcomes were collected from the electronic medical records.

Of 157 patients with COVID-19, 63 (40.1\%) presented with 1 or more GI symptoms (anorexia, nausea, or diarrhea). The mean age of 157 patients was 49.3 years (standard deviation, SD, 14.5), and 74 (47.1\%) were male.
Of the 63 patients, 21 (33.3\%) had nausea, $47(74.6 \%)$ had anorexia, and 25 (39.7\%) had diarrhea. The mean age of those patients was 51.9 years (SD, 14.9). Twentyfour $(38.1 \%)$ were male, and 24 (38.1\%) had chronic diseases. The most common symptoms were cough, fatigue, fever, and muscle soreness. Neither the median white blood cell nor lymphocyte counts were different between patients with and without GI symptoms (Table 1).

There was no significant difference in viral shedding, the time to clinical recovery, or hospitalization duration between patients with and without GI symptoms (Table 1). Among patients with GI symptoms, $63.5 \%$ received corticosteroids treatment, which is much lower than patients without GI symptoms group (63.5\% vs $76.6 \% ; p=0.0751$ ). Moreover, less patients with GI symptoms developed into severe cases compared with those without GI symptoms $(12.7 \%$ vs $35.1 \%$; $p=0.0016)$.

In our experience, 4 out of 10 patients with COVID19 have significant GI symptoms. There was no significant difference in gender, age, and comorbidities between patients with and without GI symptoms. Leukocyte and lymphocyte counts were similar between the two groups. Besides, there was no significant difference in viral shedding, the time to clinical recovery, or hospitalization duration between patients with and

\footnotetext{
* Correspondence: chxmin@hotmail.com

${ }^{\dagger}$ Chao Cao, Meiping Chen and Li He contributed equally to this work.

${ }^{4}$ Department of Cardiology, Ningbo First Hospital, 59 Liuting Road, Ningbo, Zhejiang province, China

Full list of author information is available at the end of the article
} 
Table 1 Demographics and clinical features of coronavirus disease 2019

\begin{tabular}{|c|c|c|c|c|}
\hline & Total $(\boldsymbol{n}=157)$ & Gl symptoms $(\boldsymbol{n}=63)$ & Without Gl symptoms $(\boldsymbol{n}=94)$ & $\boldsymbol{p}$ value* \\
\hline Age, mean (SD), years & $49.3(14.5)$ & $51.9(14.9)$ & $47.5(14.0)$ & 0.0599 \\
\hline \multicolumn{5}{|l|}{ Gender } \\
\hline Male & $74(47.1 \%)$ & $24(38.1 \%)$ & $50(53.2 \%)$ & \multirow[t]{2}{*}{0.0633} \\
\hline Female & $83(52.9 \%)$ & 39 (61.9\%) & $44(46.8 \%)$ & \\
\hline \multicolumn{5}{|l|}{ Comorbidities } \\
\hline Hypertension & $28(17.8 \%)$ & $12(19.1 \%)$ & $16(17.0 \%)$ & 0.7451 \\
\hline Diabetes & $9(5.7 \%)$ & $5(7.9 \%)$ & $4(4.3 \%)$ & 0.5337 \\
\hline Chronic kidney disease & $3(1.9 \%)$ & $1(1.6 \%)$ & $2(2.1 \%)$ & 1.0000 \\
\hline Chronic lung disease & $2(1.3 \%)$ & $1(1.6 \%)$ & $1(1.1 \%)$ & 1.0000 \\
\hline Heart disease & $2(1.3 \%)$ & $2(3.2 \%)$ & 0 & 0.1595 \\
\hline Malignancy & $4(2.6 \%)$ & $1(1.6 \%)$ & $3(3.2 \%)$ & 0.9135 \\
\hline Total with $\geq 1$ comorbidity & $55(35.0 \%)$ & $24(38.1 \%)$ & $31(33.0 \%)$ & 0.5101 \\
\hline \multicolumn{5}{|l|}{ Symptoms } \\
\hline Fever & 65 (41.4\%) & $23(36.5 \%)$ & $42(44.7 \%)$ & 0.3082 \\
\hline Cough & $109(69.4 \%)$ & $47(74.6 \%)$ & $62(66.0 \%)$ & 0.2491 \\
\hline Sore throat & $12(7.6 \%)$ & $4(6.4 \%)$ & $8(8.5 \%)$ & 0.8468 \\
\hline Muscle soreness & $44(28.0 \%)$ & $23(36.5 \%)$ & $21(22.3 \%)$ & 0.0527 \\
\hline Fatigue & $73(46.5 \%)$ & $44(69.8 \%)$ & $29(30.9 \%)$ & $<0.001$ \\
\hline \multicolumn{5}{|l|}{ Initial laboratory parameters, median (IQR) } \\
\hline WBCs count, $\times 10^{9} / \mathrm{L}$ & $4.9(3.8-6.3)$ & $4.9(3.4-6.0)$ & $5.0(4.0-6.4)$ & 0.4838 \\
\hline Lymphocyte count, $\times 10^{9} / \mathrm{L}$ & $1.0(0.7-1.4)$ & $1.0(0.7-1.4)$ & $1.0(0.7-1.5)$ & 0.4423 \\
\hline C-reactive protein, mg/L & $13.2(3.4-32.9)$ & $17.8(7.2-41.1)$ & $9.1(2.9-30.3)$ & 0.0561 \\
\hline ALT level, IU/L & $21.7(15.4-38.8)$ & $23.1(15.0-43.0)$ & $21.7(16.2-34.3)$ & 0.8062 \\
\hline AST level, IU/L & $26.2(20.7-34.7)$ & $26.0(20.0-35.0)$ & $26.9(20.8-34.7)$ & 0.7189 \\
\hline Severe cases & $41(26.1 \%)$ & $8(12.7 \%)$ & $33(35.1 \%)$ & 0.0016 \\
\hline Corticosteroid usage & $112(71.3 \%)$ & $40(63.5 \%)$ & $72(76.6 \%)$ & 0.0751 \\
\hline \multicolumn{5}{|l|}{ Hospital course, mean (SD), days } \\
\hline Duration onset to treatment & $5.3(5.4)$ & $5.9(6.0)$ & $4.9(4.9)$ & 0.2580 \\
\hline Clinical recovery time & $9.8(4.9)$ & $10.7(4.5)$ & $9.1(5.2)$ & 0.0607 \\
\hline Time of virus nucleic acid turn to negative & $12.4(6.4)$ & $13.0(6.1)$ & $12.0(6.7)$ & 0.3509 \\
\hline Hospitalization duration & $16.0(4.9)$ & $16.1(5.1)$ & $15.8(4.7)$ & 0.7003 \\
\hline
\end{tabular}

Gl gastrointestinal, IQR interquartile range, $S D$ standard deviation, WBC white blood cell, $A L T$ alanine aminotransferase, AST aspartate aminotransferase

* $P$ values indicate differences between patients with $\mathrm{Gl}$ symptoms and those without. $P<0.05$ was defined as statistically significant

without GI symptoms. Nonetheless, less patients with GI symptoms received corticosteroids and developed into severe cases.

This study suggested that GI symptoms in COVID-19 are frequent but are not associated with the severity of diseases or worse outcomes. However, because SARS-CoV-2 can be found in patient feces and the digestive system, we should be cautious with these potential routes for transmission $[2,3]$. This study is limited by the lacked of data of reverse transcriptase polymerase chain reaction on COVID-19 in GI specimens. Our observations indicate that a substantial number of patients present with predominantly GI symptoms, and caution about this atypical presentation is necessary.
Abbreviations

COVID-19: Coronavirus disease 2019; SARS-CoV-2: Severe acute respiratory syndrome coronavirus 2; GI: Gastrointestinal; IQR: Interquartile range; SD: Standard deviation; WBC: White blood cell; ALT: Alanine aminotransferase; AST: Aspartate aminotransferase

\section{Acknowledgements}

Not applicable.

Authors' contributions

$C C, L H, J X$, and $X C$ design the study; $C C, M C, L H$, and JX acquired and interpreted the data; $C C, M C$, and JX analyzed the data and wrote the paper; XC supervised the study. All authors have seen and approved the final draft.

\section{Funding}

This work was supported by the Medical and Health Program of Zhejiang (2019KY156 and 2019KY563). 


\section{Availability of data and materials}

Participant data without names and identifiers will be made available after approval from the corresponding author.

\section{Ethics approval and consent to participate}

Ethical approvals for this study were obtained from the Ethics Commission of Ningbo First Hospital (2020-R017) and the Ethics Commission of Jingzhou Central Hospital (2020-2-19). Written informed consent was waived due to the rapid emergence of this disease.

\section{Consent for publication}

Not applicable.

\section{Competing interests}

Authors have disclosed no conflicts of interest.

\section{Author details}

'Department of Respiratory and Critical Care Medicine, Ningbo First Hospital, Ningbo, China. ${ }^{2}$ Department of Respiratory and Critical Care Medicine, Jingzhou Central Hospital, the Second Clinical Medical College, Yangtze University, Jingzhou, China. ${ }^{3}$ Department of Respiratory and Critical Care Medicine, Hubei Provincial Hospital of Integrated Chinese \& Western Medicine, Wuhan, China. ${ }^{4}$ Department of Cardiology, Ningbo First Hospital, 59 Liuting Road, Ningbo, Zhejiang province, China.

Received: 13 May 2020 Accepted: 27 May 2020

Published online: 15 June 2020

\section{References}

1. Zhu N, Zhang D, Wang W, Li X, Yang B, Song J, et al. A novel coronavirus from patients with pneumonia in China, 2019. N Engl J Med. 2020;382(8): 727-33.

2. Guan WJ, Ni ZY, Hu Y, Liang WH, Ou CQ, He JX, et al. Clinical characteristics of coronavirus disease 2019 in China. N Engl J Med. 2020;382(18):1708-20.

3. Holshue ML, DeBolt C, Lindquist S, Lofy KH, Wiesman J, Bruce H, et al. First case of 2019 novel coronavirus in the United States. N Engl J Med. 2020; 382(10):929-36

4. Luo S, Zhang X, Xu H. Don't overlook digestive symptoms in patients with 2019 novel coronavirus disease (COVID-19). Clin Gastroenterol Hepatol. 2020;18(7):1636-7.

5. World Health Organization. Clinical management of severe acute respiratory infection when COVID-19 is suspected: interim guidance, 13 March 2020 Available from: https://www.who.int/publications-detail/clinicalmanagement-of-severe-acute-respiratory-infection-when-novel-coronavirus(ncov)-infection-is-suspected. Accessed 18 Mar 2020.

\section{Publisher's Note}

Springer Nature remains neutral with regard to jurisdictional claims in published maps and institutional affiliations. 